\title{
Minimum Inhibitory Concentration Test
}

National Cancer Institute

\section{Source}

National Cancer Institute. Minimum Inhibitory Concentration Test. NCI Thesaurus. Code C128985.

A laboratory test to determine the lowest concentration of a substance that will inhibit a biological or biochemical function, such as microorg anism growth or enzymatic activity. 